\title{
Gesture Mahasiswa dalam Menyelesaikan Masalah Kombinatorika dengan Jawaban Benar Berdasarkan Tahap Berpikir Mason
}

\author{
Mei Radia Putri ${ }^{1}$, Abdur Rahman As' ari $^{1}$, Sisworo ${ }^{1}$ \\ ${ }^{1}$ Pendidikan Matematika-Universitas Negeri Malang
}

\begin{tabular}{l}
\hline \hline INFO ARTIKEL \\
\hline Riwayat Artikel: \\
Diterima: 16-03-2020 \\
Disetujui: 27-08-2020 \\
\hline
\end{tabular}

\section{Kata kunci:}

gesture;

combinatorics;

the Mason thinking stage;

gesture;

kombinatorika;

tahap berpikir Mason

\author{
Alamat Korespondensi: \\ Mei Radia Putri \\ Pendidikan Matematika \\ Universitas Negeri Malang \\ Jalan Semarang 5 Malang \\ E-mail:meiradia9@gmail.com
}

\begin{abstract}
ABSTRAK
Abstract: This study described undergraduate students' gesture in problem solving based on the stage of thinking by Mason which consisted of the stage of entry, attack, and review. The study adopted descriptive qualitative approach. Subjects were chosen based on their response in problem solving. Data collection was carried out by administering test, conducting interview, and recording video to explore students' gesture in problem solving. Results showed that the students that could answer the combinatorical problems given correctly, did pointing and writing gesture in the phases of entry and attack and acted pointing, representational, and writing gesture in review phase.
\end{abstract}

\begin{abstract}
Abstrak: Penelitian ini bertujuan untuk mendeskripsikan gesture mahasiswa dalam menyelesiakan masalah dengan jawaban benar berdasarkan tahap berpikir Mason. Sehingga peneliti dapat mengetahui jenis gesture yang dilakukan mahasiswa pada setiap tahap entry, attack, maupun review. Penelitian ini menggunakan pendekatan kualitatif deskriptif. Subjek penelitian ini diambil berdasarkan jawaban mahasiswa dalam menyelesaikan masalah dengan tepat. Pengumpulan data dilakukan dengan pemberian lembar tes, wawancara, dan video recorder untuk mengetahui gesture mahasiswa tersebut saat menyelesaikan masalah. Hasil menunjukkan mahasiswa yang dapat menjawab masalah kombinatorika dengan benar, pada fase entry dan attack melakukan gesture pointing dan writing. Pada fase review melakukan gesture pointing, representational, dan writing.
\end{abstract}

Memecahkan masalah kombinatorika memerlukan kemampuan berpikir analitik (Sari \& Saragih, 2019; Yunis, dkk, 2018). Menurut Abdillah, dkk (2018). Berpikir analitik merupakan salah satu proses berpikir yang dimiliki seseorang dalam menyelesaikan masalah. Berpikir merupakan aktivitas mental yang membantu dalam memahami masalah, membuat keputusan, dan memecahkan masalah (Subanji, 2011). Proses berpikir dalam menyelesaikan masalah merupakan kegiatan seseorang pada saat melakukan proses penemuan solusi (Khamidah, 2017; Safrida, dkk, 2015; Sucipto, 2018; Widyastuti, dkk, 2007; Yani, dkk, 2016). Proses berpikir siswa dalam menyelesaikan masalah biasanya memiliki tahapan-tahapan yang harus dilalui. Kusaeri, et al (2018) menyatakan bahwa pemahaman terhadap langkah-langkah penyelesaian masalah memudahkan guru mengetahui proses berpikir siswanya. Penelusuran proses berpikir dapat menggunakan fase-fase yang dikemukakkan oleh Mason. Menurut Mason dkk, (2010) terdapat tiga fase proses berpikir yang berkaitan dengan pemecahan masalah matematika, yaitu fase entry, attack, dan fase review. Fase entry yang memuat aspek (know, want, dan introduce) yaitu ketika seseorang mencari maksud dari sebuah permasalahan, fase attack merupakan fase inti yaitu fase ketika menjalankan rencana penyelesaian masalah dan memuat aspek (try, maybe, dan why), sedangkan fase review merupakan kegiatan melihat kembali jawaban yang dikerjakan dan memuat aspek (check, reflect, dan extend).

Proses berpikir seseorang tidak hanya dilihat dari cara ia menuliskan jawaban (menyelesaikan masalah) maupun lisannya, tetapi juga dapat dilihat dari gerakan (gesture) (Beilock \& Goldin-Meadow, 2010; Francaviglia \& Servidio, 2011; Mustafa, dkk, 2016; Ng \& Sinclair, 2013; Radford, 2009; Yoon, dkk, 2011). Hal ini dikarenakan gesture dapat memfasilitasi dan membantu proses berpikir (Alibali, dkk, 2011; Arzarello, dkk, 2009). Selain itu, gesture tidak hanya merefleksikan dan mengomunikasikan pemikiran tetapi juga dapat mengubahnya dan menghasilkan wawasan matematika yang baru (Beilock \& Goldin-Meadow, 2010; Yoon, dkk, 2011). 
Gesture memiliki beberapa manfaat dalam pembelajaran matematika. Hasil penelitian Broaders, dkk, (2007) menunjukkan bahwa dengan gesture, siswa yang tidak dapat memecahkan masalah matematika seringkali memperoleh strategi pemecahan masalah yang baru dan benar. Bahkan, mereka mungkin dapat lebih berhasil dalam memecahkan masalah ketimbang yang tidak melakukan gesture. Gesture juga dapat memudahkan guru dalam mengidentifikasi aspek dari masalah yang dihadapi siswa, sejauh mana pemahaman siswa, dan keadaan dari kepastian dan ketidakpastian kognitif siswa (Reynolds \& Reeve, 2002).

Gesture merupakan bagian dari aktivitas yang terjadi secara spontan, tanpa disadari dan ditandai dengan gerakan jari, tangan, dan lengan (Mcneill, 2014). Gesture pada penelitian ini yaitu gerakan tangan mahasiswa yang muncul untuk mengomunikasikan ide secara sengaja maupun tidak sengaja (spontan) selama pemecahan masalah berlangsung. Selain itu, gesture yang digunakan pada penelitian ini merujuk pada Alibali \& Nathan (2007) yang telah memodifikasi jenis gesture yang diungkapkan McNeill, yaitu: gesture pointing (deiktik), gesture representational (ikonik dan metaforik) dan gesture writing (menulis). Dari penjelasan di atas, kita dapat melihat proses berpikir mahasiswa melalui gesture yang mereka lakukan. Berkaitan dengan kerangka berpikir Mason, mempelajari gesture yang dilakukan mahasiswa mulai dari tahap entry, attack, sampai review tentunya merupakan hal yang penting. Kita dapat mengetahui kapan seorang siswa stuck dalam memecahkan masalah dan kapan ia menemukan ide, prosedur, dan solusi dari suatu masalah sehingga memudahkan guru dalam memberikan tindak lanjut dalam pembelajaran matematika.

Berdasarkan penjelasan di atas, dapat dibentuk rumusan masalah pada penelitian ini yaitu, bagaimana gesture yang dilakukan mahasiswa dalam menyelesaikan masalah dengan benar berdasarkan tahap berpikir Mason. Dengan demikian, didapat tujuan penelitian ini adalah pendekripsian gesture yang dilakukan mahasiswa dalam menyelesaikan masalah kombinatorika dengan jawaban benar berdasarkan tahap berpikir Mason, yaitu entry, attack, maupun review.

\section{METODE}

Penelitian ini termasuk penelitian deskriptif dengan pendekatan kualitatif. Hal ini dikarenakan tujuan peneliti yaitu mendeskripsikan gesture mahasiswa dalam menyelesaikan masalah dengan benar pada setiap tahapan berpikir Mason yaitu entry, attack, dan review. Pendeskripsian ini dilakukan melalui pengamatan langsung yaitu dengan menganalisis hasil pekerjaan mahasiswa dan gesture yang dilakukan dalam menyelesaikan masalah yang diberikan serta hasil wawancara yang dilakukan. Subjek penelitian ini adalah dua mahasiswa yang dapat menjawab benar masalah kombinatorika yang diberikan. Pada penelitian ini, klasifikasi gesture yang digunakan adalah menurut Alibali \& Nathan (2011), yaitu gesture pointing, representational, dan writing.

Instrumen penelitian ini meliputi soal kombinatorika dan pedoman wawancara. Soal kombinatorika diberikan kepada subjek untuk mengetahui proses berpikir subjek berdasarkan kerangka berpikir Mason. Pada setiap tahapan Mason akan dilihat gesture apa saja yang dilakukan subjek untuk menyelesaikan masalah. Pedoman wawancara digunakan untuk mempermudah peneliti mewawancarai terkait gesture yang dilakukan subjek pada setiap fase Mason. Karena penelitian ini berfokus pada gesture yang dilakukan mahasiswa selama memecahkan masalah sehingga untuk memperoleh data yang akurat peneliti merekam semua kegiatan mahasiswa selama proses pemecahan masalah berlangsung.

Penelitian ini dilakukan pada akhir bulan Desember 2019 sampai Januari 2020. Pengambilan data dilakukan selama empat minggu dengan tiga minggu memberikan berupa soal kombinatorika dan satu minggu yang kemudian dilanjutkan dengan wawancara. Analisis data yang digunakan pada penelitian ini mengacu analisis data menurut Creswell (2011) yang meliputi mempersiapkan alat penelitian yang digunakan untuk memperoleh data yang diinginkan berupa soal kombinatorika, pedoman wawancara, dan video recorder. Langkah selanjutnya pengambilan data dari subjek penelitian. Pengambilan data berupa pemberian soal kombinatorika dan wawancara terkait gesture yang dilakukan. Keseluruhan data yang diperoleh kemudian dilakukan reduksi data untuk memilah data mana yang dapat digunakan dan tidak dapat digunakan dalam penelitian. Setelah data diperoleh, data di olah untuk mendapatkan jawaban terkait rumusan masalah penelitian.

\section{HASIL}

Berikut akan dijelaskan hasil dari jawaban dua mahasiswa yaitu S1 dan S2 dan gesture yang dilakukan saat menyelesaikan masalah berdasarkan kerangkan berpikir Mason, yaitu entry, attack, dan review.

\section{Deskripsi Jawaban S1 dan Gesture yang Dilakukan Saat Menyelesaikan Masalah}

Berikut merupakan jawaban S1 pada fase entry pada soal nomor 1 serta gesture yang dilakukan pada setiap tahap berpikir Mason. 


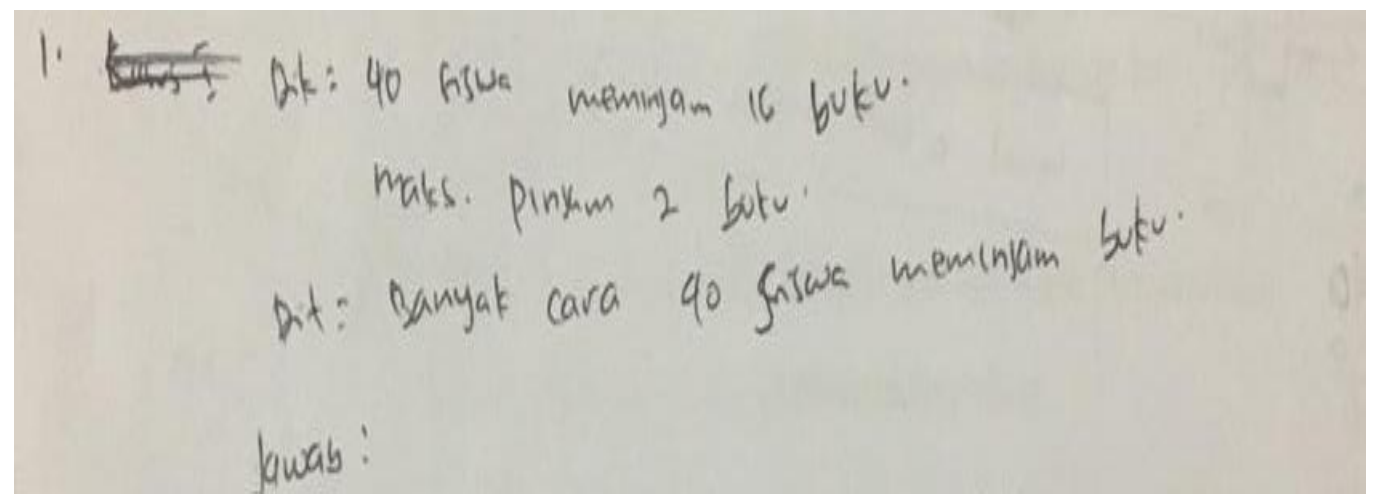

Gambar 1. Jawaban S1 yang Menunjukkan Fase Entry

Pada proses penyelesaian masalah pada fase entry, S1 melakukan beberapa gesture seperti yang terlihat pada gambar 2. Berikut akan dijelaskan terkait gesture yang dilakukan pada fase entry dalam menyelesaikan soal nomor 1.

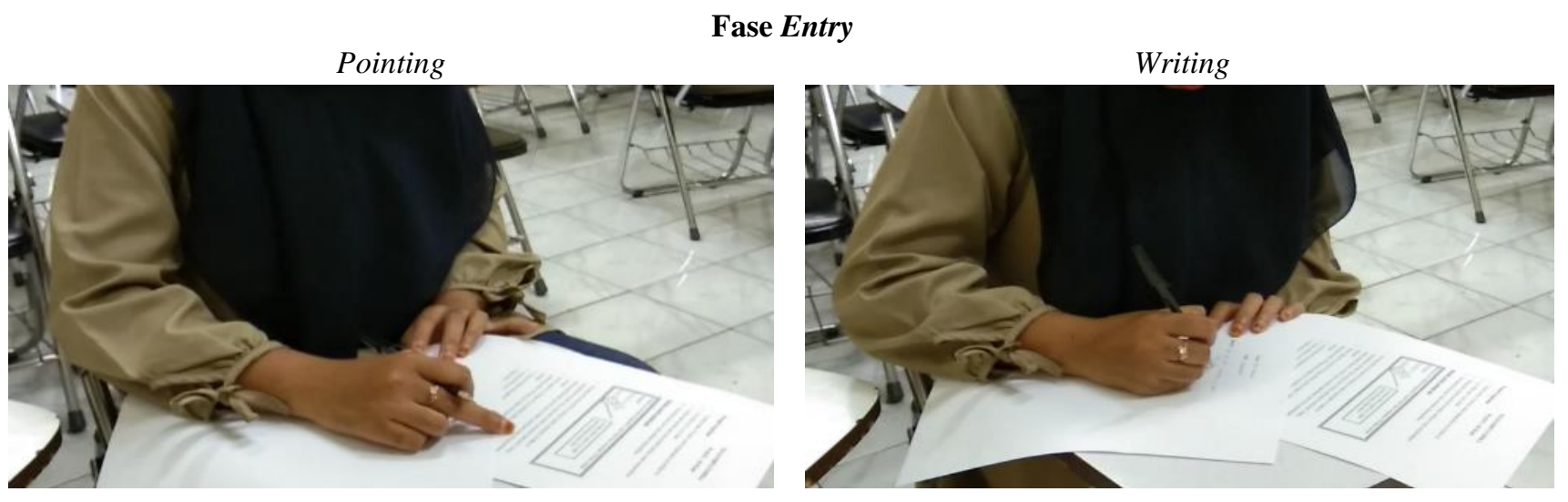

Gambar 2. Gesture Pointing dan Writing yang Dilakukan S1 pada Fase Entry

Dalam pengambilan data, peneliti melakukan wawancara dengan S1 untuk menanyakan terkait gesture yang dilakukan selama penyelesaian masalah nomor 1 terkhusus pada fase entry. Gesture yang dilakukan oleh S1 adalah pointing dan writing. Gesture pointing digunakan ketika menujuk suatu gambar, lokasi, orang, atau benda. Selain itu, biasanya gesture menunjuk dilakukan dengan ibu jari, jari telunjuk, jari tengah, maupun suatu benda (bolpoin) yang dipegangnya. Gesture writing berupa gerakan untuk menulis informasi, menulis hasil, maupun menghitung sesuai dengan masalah yang diberikan. berdasarkan wawancara yang dilakukan dengan S1 menunjukan bahwa gesture pointing (menunjuk) membantu untuk lebih fokus dalam penyelesaian masalah yang diberikan. Sedangkan gesture writing ketika S1 mencoba menuliskan apa yang diketahui dan apa yang ditanya pada soal nomor 1 .

"Saya melakuan gerakan tersebut saat membaca soal agar dapat lebih fokus menemukan apa yang diketahui dan ditanyakan dari soal." (W/S1/140120)

Menurut S1 dengan melakukan gesture tersebut, pemecahan masaah akan lebih mudah jika mengetahui terlebih dahulu informasi yang tertera daam soal serta mengetahui apa yang menjadi permasalahan dalam soal tersebut. Setelah ditelusuri lebih jauh, S1 menggunakan gesture tersebut dalam memudahkan perencanaan penyelesaian masalah yang sedang dikerjakan.

"Saya melakukan gestur tersebut untuk lebih fokus menyusun rencana penyelesaian masalah. Secara spontan gerakan itu muncul saat saya ingin lebih fokus dalam menyusun rencana penyelesaian." (W/S1/140120)

Hasil wawancara di atas menunjukan bahwa pada tahap entry S1 melakuan gesture pointing dan writing untuk lebih fokus dalam menemukan informasi serta menyajikan informasi tersebut ke dalam sebuah rencana dan rancangan penemuan solusi dalam penyelesaian masalah yang diberikan. Selanjutnya, akan diperlihatkan jawaban S1 pada saat fase attack dan gesture yang dilakukan pada saat fase tersebut. 


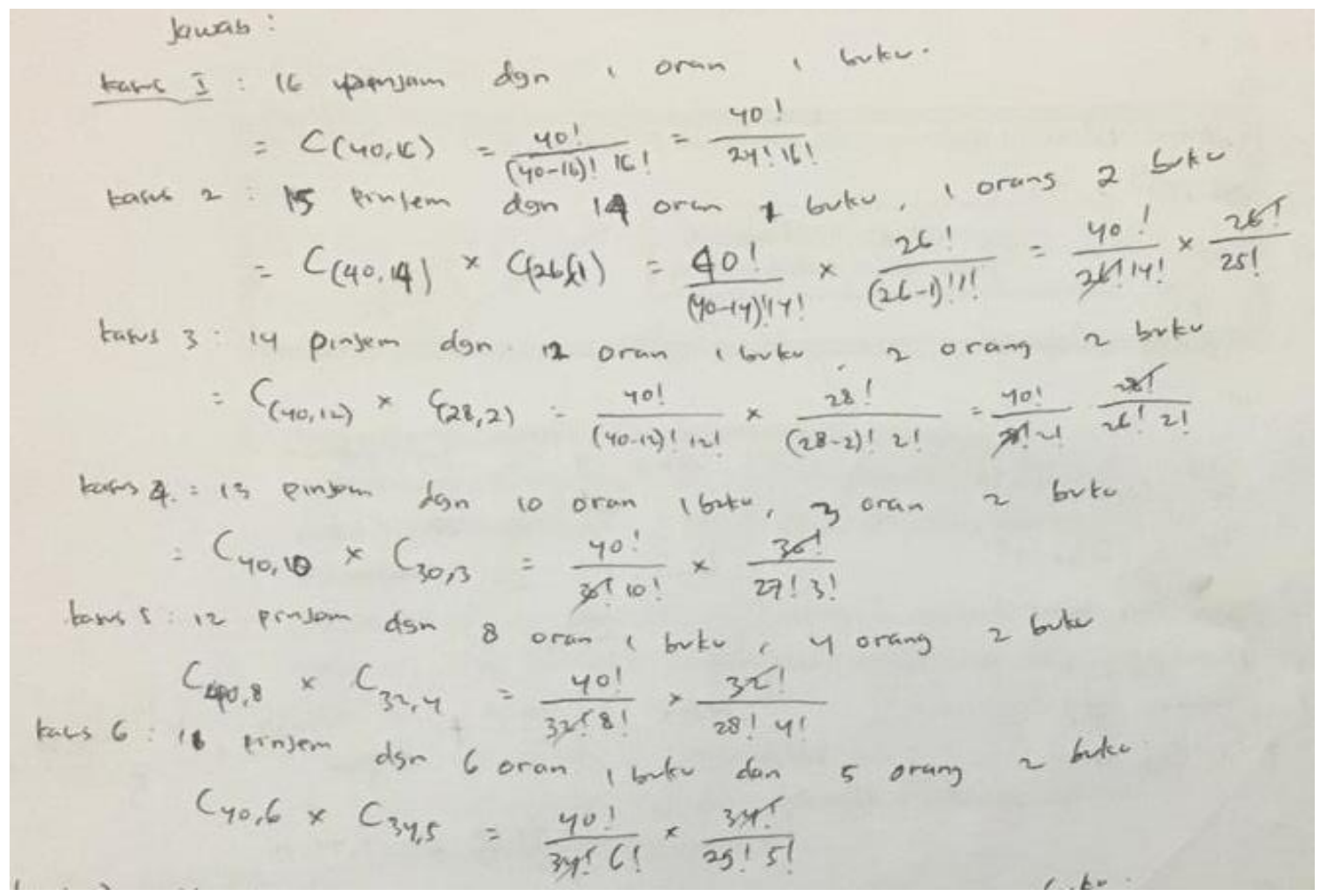

Gambar 3. Jawaban S1 yang Menunjukkan Fase Attack

Selain pada tahap entry S1 melakukan gesture yang sama pada tahap attack, namun gesture yang dilakukan berbeda tujuannya. Berikut diperlihatkan gesture S1 pada fase attack pada soal nomor 1.

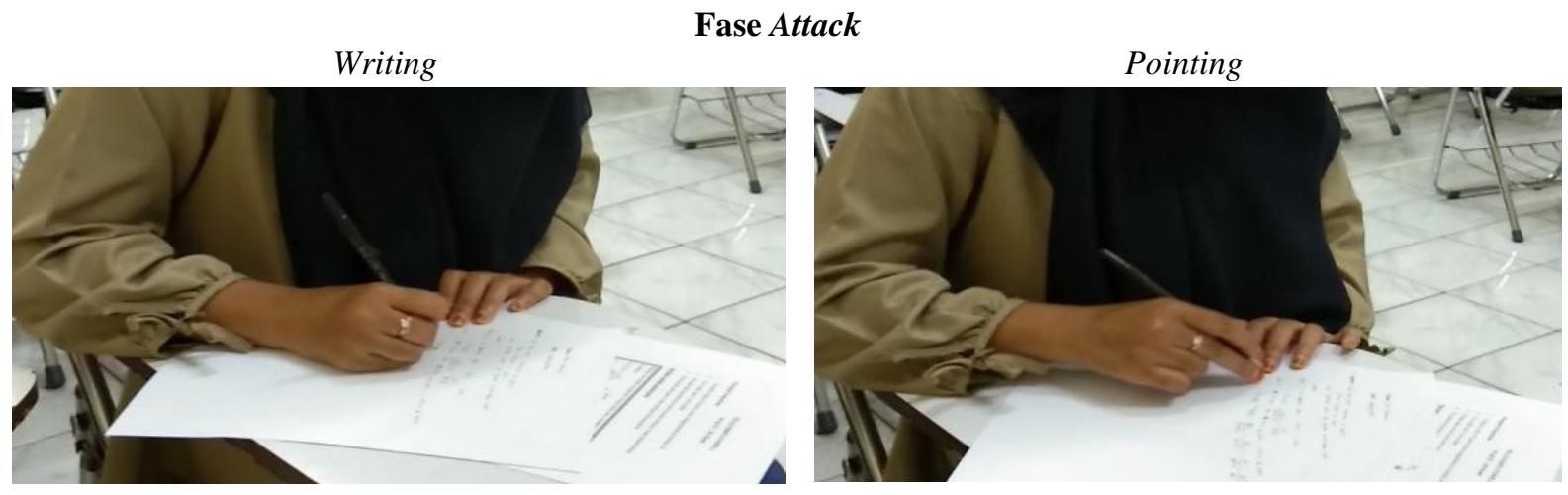

Gambar 4. Gesture Pointing dan Writing yang Dilakukan S1 pada Fase Attack

Menurut S1 gesture pointing dan writing yang dilakukan bertujuan untuk memudahkan memikirkan setiap kasus-kasus yang mungkin terjadi pada penyelesaian masalah ini. Berikut hasil wawancara terkait gesture yang dilakukan pada fase attack.

"Itu saya lagi memikirkan setiap kasus yang mungkin, itukan ada beberapa kasus ya yang harus dijabarkan, seperti kasus 1 itu artinyakan terdapat 16 siswa yang meminjam 1 buku, terus kalau kasus 2 ada 15 siswa, nah itu saya mikir dari 15 siswa itu berapa yang pinjam 1 buku dan berapa yang pinjam 2 buku, dsb." (W/S1/140120)

Berdasarkan wawancara di atas, terlihat S8 menggunakan gesture pointing dan writing untuk menyusun rencana yang dibuat dan memudahkan memikirkan setiap kasus yang mungkin terjadi. Selain fase entry dan attack, S1 juga memenuhi fase review dan juga melakukan gesture saat fase review berlangsung. Berikut merupakan jawaban S1 pada saat fase review. 


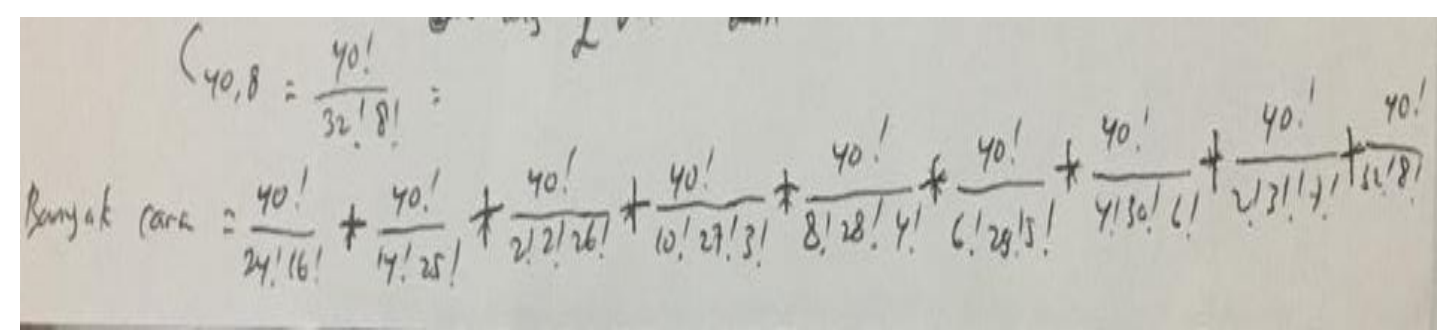

\section{Gambar 5. Jawaban S1 yang Menunjukkan Fase Review}

Berdasarkan pada gambar di atas, pada fase review S1 juga melakukan gerakan-gerakan yang berguna dalam proses pemecahan masalah berlangsung. Bedahalnya pada ke dua fase sebelumnya, gesture yang dilakukan S1 pada fase review bertambah satu yaitu getsure representational. Dapat dilihat pada Gambar 6, gesture yang dilakukan pada fase ini yaitu getsure writing, pointing, dan representational.

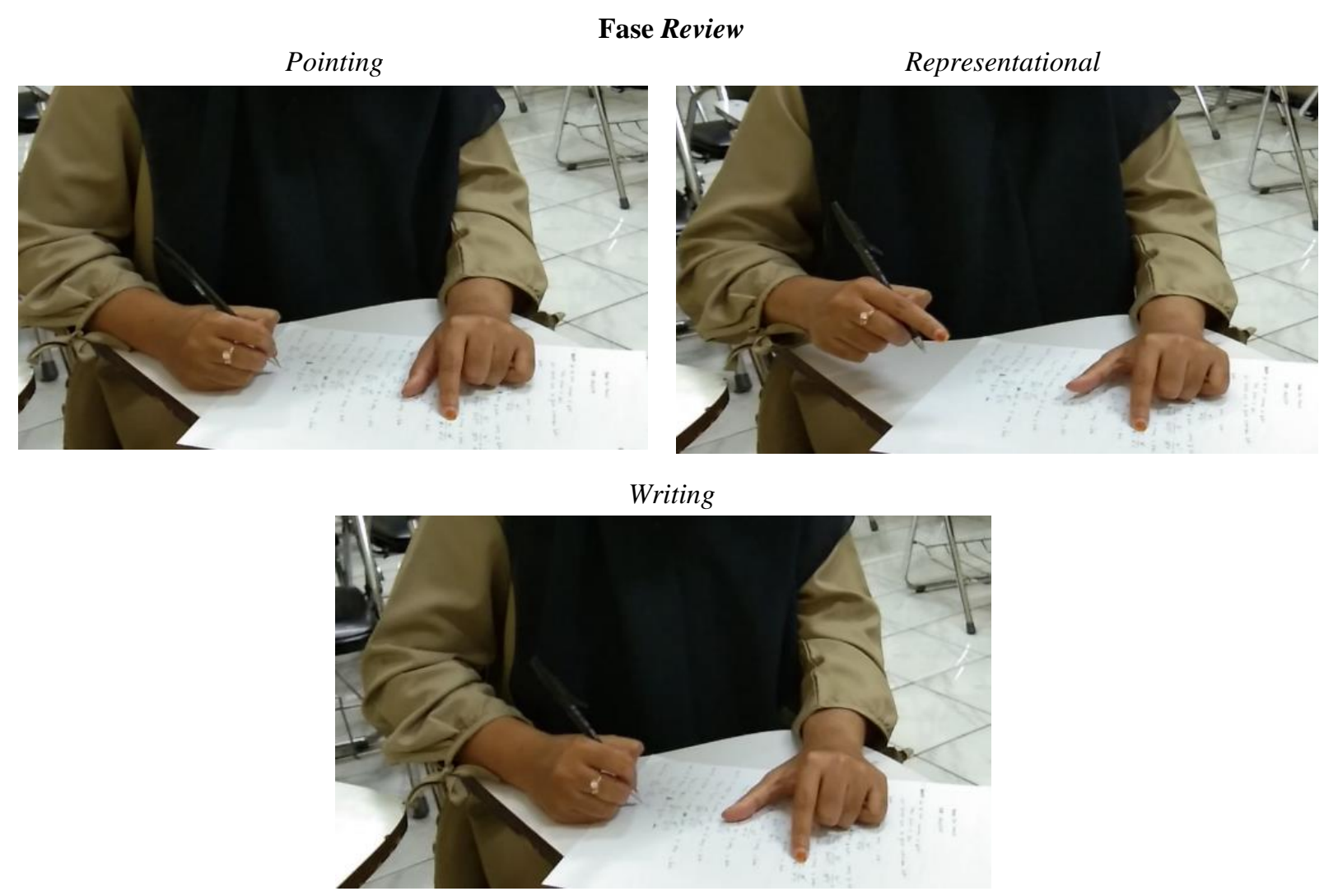

\section{Gambar 6. Gesture Pointing, Representational, dan Writing yang Dilakukan S1 pada Fase Review}

Berbeda halnya dengan fase entry dan attiack gesture yang dilakukan S1 pada fase review yaitu pointing, representational, dan writing. Dalam wawancara dengan S1, S1 mengatakan tujuan melakukan gesture tersebut adalah untuk mendikte setiap kasus yang telah didapat serta menghitung kasus yang didapat yang ada yang kemudian dituliskan agar menjadi kesimpulan dari apa yang ditanya pada masalah tersebut.

"Saya menunjuk seperti mendikte setiap kasus yang saya selesaikan yang kemudian menuliskan berapa banyak 40 siswa meminjam 16 buku. Habis itu, saya disitu menghitung menggunakan jari untuk lebih mudah dalam menghitung kasus yang saya peroleh" (W/S1/140120)

Kemudian, ketika peneliti bertanya terkait apakah gesture tersebut dilakukan ketika mencoba mengecek kembali masalah tersebut, jawabawan dari S1 sebagai berikut. 
Paparan di atas menunjukkan bahwa gesture yang dilakukan pada fase review berguna menyimpulkan apa yang ditanya pada masalah sambil mengecek satu persatu kasus yang dibuat agar lebih tepat. Selanjutnya, pada soal nomor 2, mahasiswa memenuhi fase entry, attack, dan review juga. Berikut akan diperlihatkan jawaban dari S1 pada soal nomor 2 . Terkait gesture yang dilakukan S1 pada soal nomor 2 tidak ada perbedaan setiap fasenya. Dimana, pada fase entry dan attack S1 melakukan gesture pointing dan writing serta ketika fase review pun S1 melakukan gesture representational, pointing, dan writing. Selain gesture yang dilakukan setiap tahap berpikir Mason itu sama seperti nomor 1, tujuan dari gesture tersebut juga sama. Sehingga, peneliti tidak memperlihatkan gesture yang dilakukan S1 pada soal nomor 2. Berikut gambar 7, 8, dan 9 terkait jawaban S1 pada fase entry, attack, dan review.

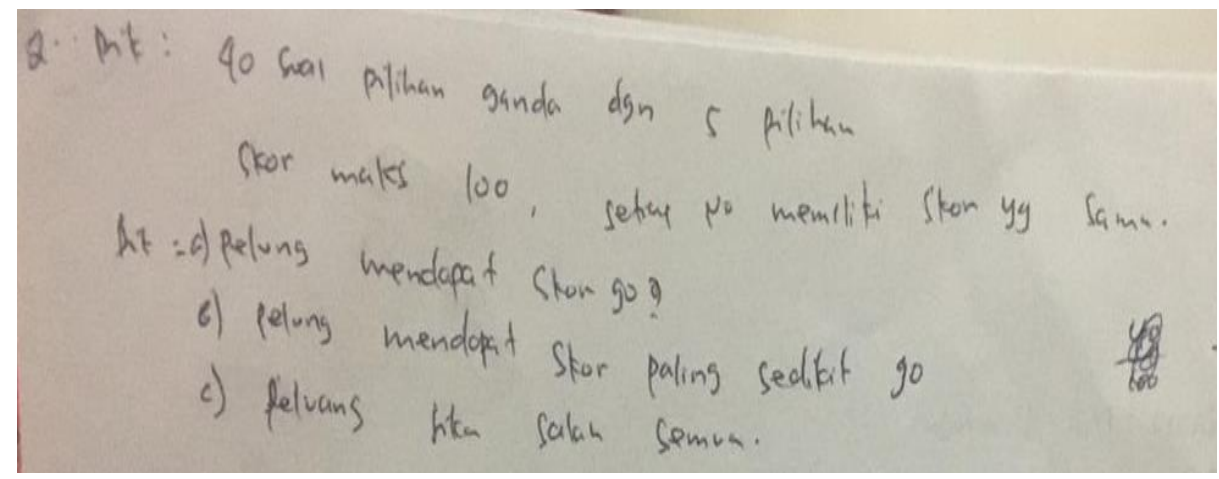

\section{Gambar 7. Jawaban S1 yang Menunjukkan Fase Entry}

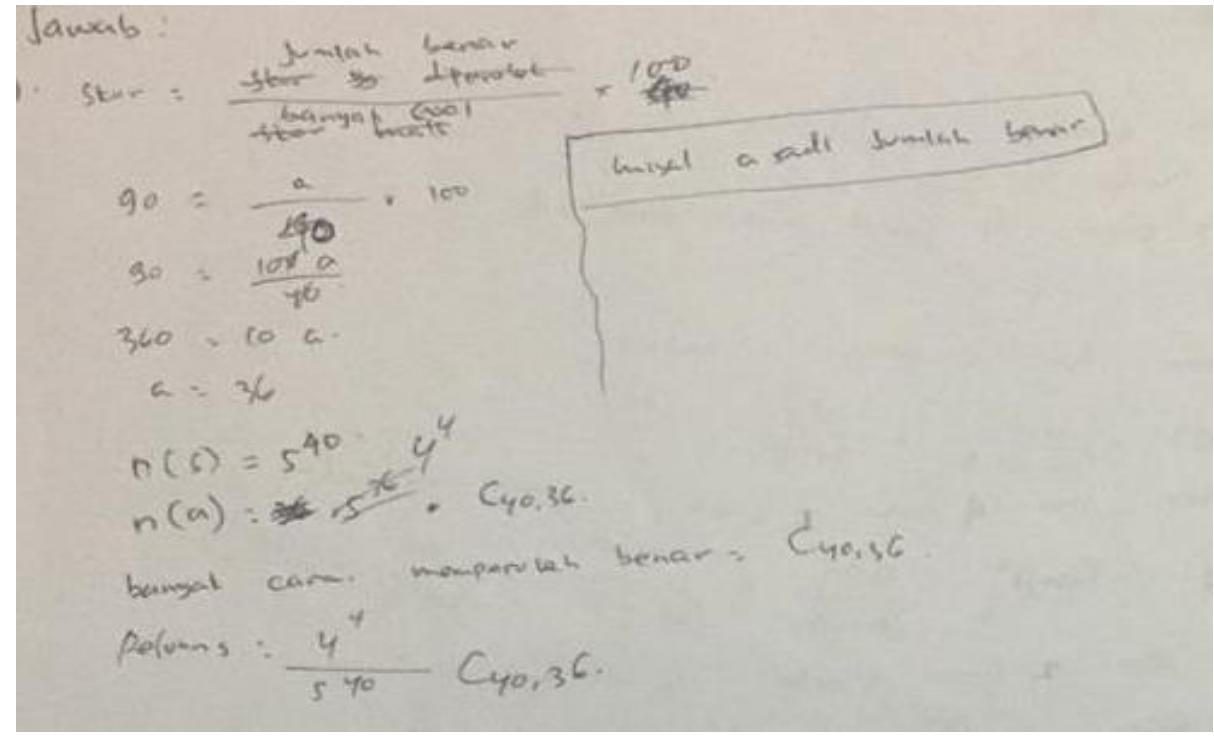

Gambar 8. Jawaban Mahasiswa yang Menunjukkan Fase Attack dan Review

\section{Deskripsi Jawaban S2 dan Gesture yang Dilakukan Saat Menyelesaikan Masalah}

Dalam pendeskirpsian ini, akan dibagi menjadi dua sub bagian, yaitu peneliti akan mendeskripsikan jawaban S2 berdasarkan setiap fase Mason serta mendekripsikan jenis gesture yang dilakukan disetiap fae Mason.

Berdasarkan Fase Mason (entry, attack, dan review). Seperti halnya S1, S2 juga memenuhi setiap tahapan berpikir Mason yaitu entry, attack, maupun review. Berikut akan diperlihatkan jawaban di setiap fasenya, serta gesture yang dilakukan pada proses pemecahan masalah berlangsung. Pada proses penyelesaian masalah ini S2 melakukan beberapa gesture seperti yang terlihat pada gambar di bawah ini. Berikut akan dijelaskan terkait gesture yang dilakukan pada saat menyelesaikan soal nomor 1 . 


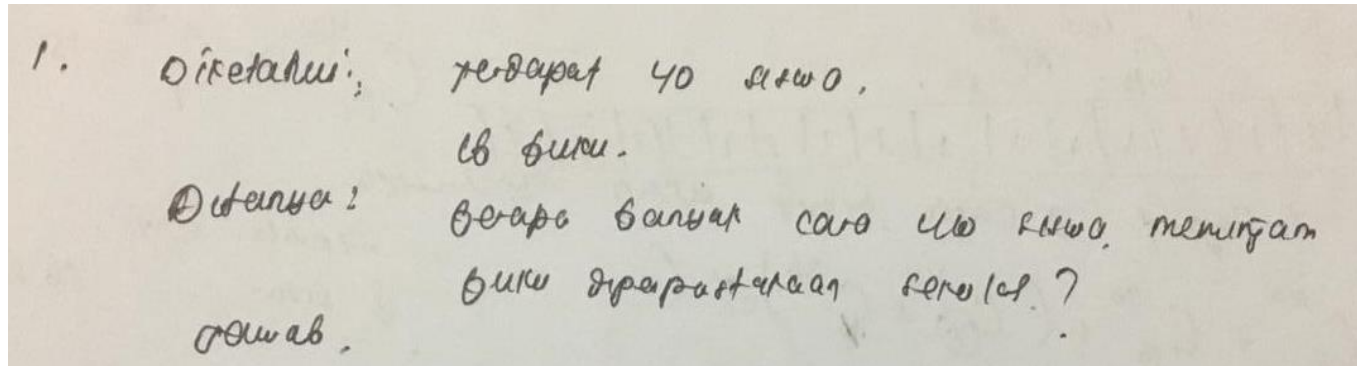



Pointing

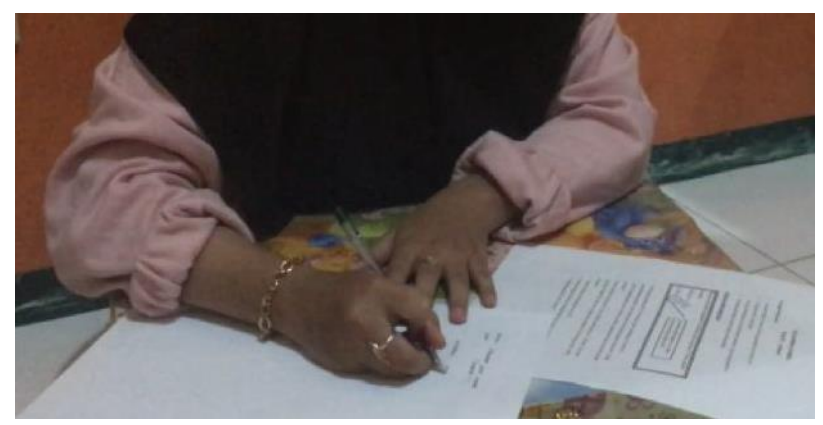

Writing

Gambar 9. Gesture Pointing dan Writing yang Dilakukan S2 pada Fase Entry

Dalam pengambilan data, peneliti melakukan wawancara dengan S2 untuk menanyakan terkait gesture yang dilakukan selama menyelesaikan masalah nomor 1. Gesture yang dilakukan oleh S2 yaitu gesture pointing dan writing. Berikut merupakan hasil pengklarifikasian setiap gesture yang dilakukan oleh S2. S2 menunjukkan gesture pointing dan writing pada fase entry. Munculnya gerakan tersebut di indetifikasi sebagai upaya agar dapat menandai hal-hal penting yang ditemukan dari soal. Hal ini sudah ditanyakan kepada S2 dan menurut penuturan subjek gesture tersebut ada kaitanya dengan proses penyelesaian masalah yang diberikan.

"Untuk memudahkan mengingat info yang ada dalam soal saya mencoba menandai info penting yang ada di soal dengan menggaris bawahinya." (W/S2/190120)

Berdasarkan pernyataan di atas menunjukkan bahwa tanda yang diberikan adalah suatu upaya S2 dalam menulisaskan informasi penting yang harus dimasukkan pada fase entry. Selain mencari informasi yang penting menandai tersebut juga di tujukan untuk memastikan apa yang menjadi pertanyaan atau permasalahan dari soal tersebut. Selanjutnya Gambar 10 merupakan jawaban S2 yang mewakili fase attack.

"Tujuan saya melakukan gesture tersebut untuk membantu saya. Membantu dalam mengingat serta memfokuskan infoinfo yang penting. Dalam proses pengumpulan informasi ini, menunjuk serta menggaris bawahi akan sangat membantu." (W/S2/190120)

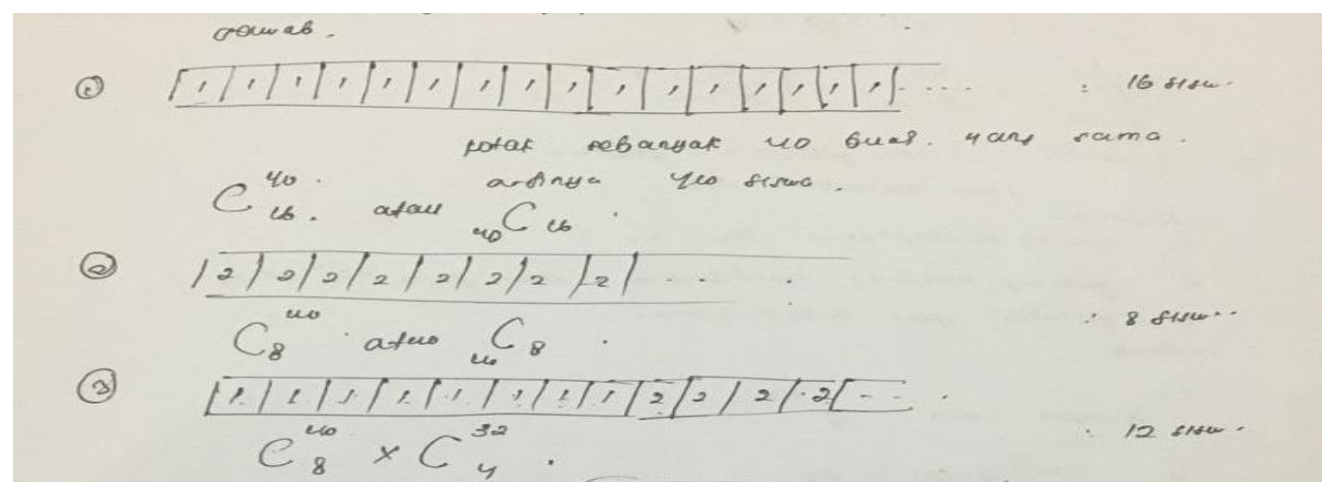

Gambar 10. Jawaban S2 yang Menunjukkan Fase Attack 
Sama halnya pada fase sebelumya, gesture yang dilakukan S2 juga sama yaitu pointing dan writing. Tentunya gesture yang dilakukan pada fase entry dan attack memiliki tujuan yang berbeda pula. Di bawah ini akan dibahas terkait klarifikasi dari tujuan dari gesture yang dilakukan S2 selama fase attack.

\section{Fase Attack}

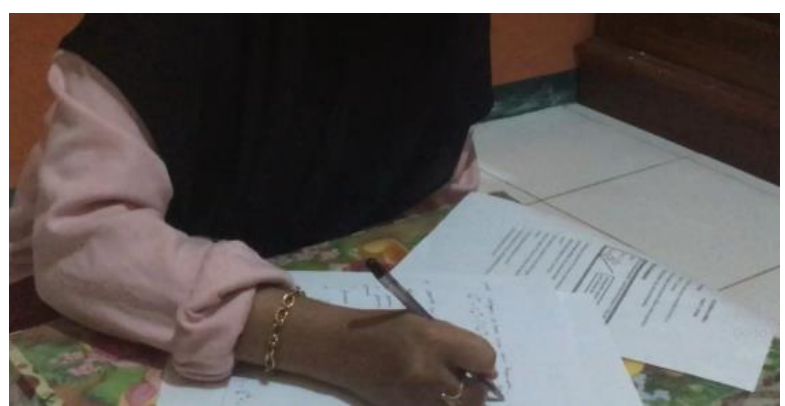

Writing

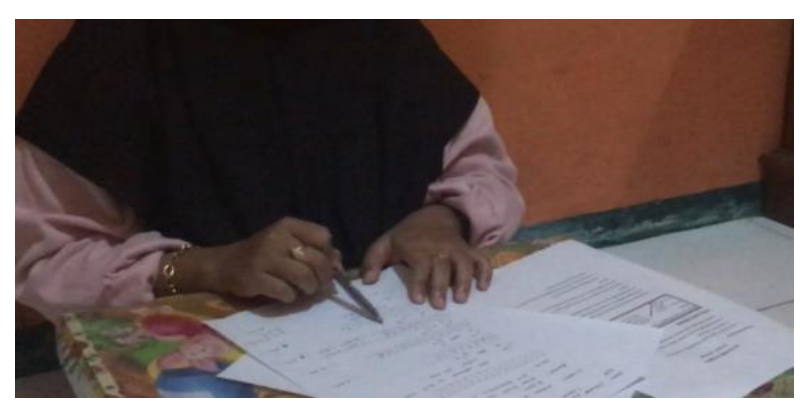

Pointing

\section{Gambar 11. Gesture Pointing dan Writing yang Dilakukan S2 pada Fase Attack}

Sama halnya dengan fase entry, fase attack juga memerlukan ketelitian yang baik. Dalam tahapannya, menyusun perncanaan serta menyelesaikan masalah perlu fokus yang tinggi. Pada fase sebelumnya telah ditulis apa saja informasi dan pertanyaan yang ditanyakan di soal. Berdasarkan wawancara dengan S2, menunjukkan bahwa apa yang dilakukan tersebut untuk memastikan yang di kerjakan sesuai dengan yang direncanakan.

"Apa yang saya tandai tadi memudahkan saya dalam penyelesaian tugas, saya tinggal menunjuk yang telah saya tulis serta menandai jika sudah saya masukkan ke dalam rancangan penyelesaian.” (W/S2/190120)

Selain itu, dalam fasa attack ada beberapa kesempatan yang telihat bahwa S2 melakukan perhitungan yang kurang tepat sehingga ia kembali membenarkan dengan cara melihat kembali serta memberi tanda ke bagian-bagian yang akan dimasukkan dan sudah dimasukkan kedalam proses penyelesaian soal. Berlaku untuk soal nomor 1 dan nomor 2 S2 cenderung melakukan pergerakan yang sama.

"Saya menandai yang sudah saya tulis dan akan saya tulis, dengan begitu dapat membantu saya dengan mudah memetakan apa yang harus saya tulis. Ini sangat membantu karena beberapa kali saya salah mengerjakan karena lupa tidak menandai mana yg sudah dan harus selanjutnya saya masukan.” (W/S2/190120)

Dari wawancara tersebut menunjukkan bahwa pada fase attack, gesture yang dilakukan subjek membantu subjek dalam penyelesaian masalah. Begitu juga dengan fase review, fase ini adalah fase ketika S2 melakukan pengecekan kembali terhadap jawaban yang telah ditemukan. Dalam pengecekan tentunya melakukan gerakan yang menunjukan ia sedang memastikan kebenaran dari jawabannya. Gesture yang dilakukan adalah representational, writing dan pointing. Menurut S2 gesture tersebut bertujuan untuk memfokuskan apa yang sedang ia cocokan dan menghitung kemabali ketepatan penentuan setiap kasus yang ia buat sebelumnya. Berikut Gambar 12 dan 13 yang mewakili jawaban S2 pada fase review dan gesture yang dilakukannya.

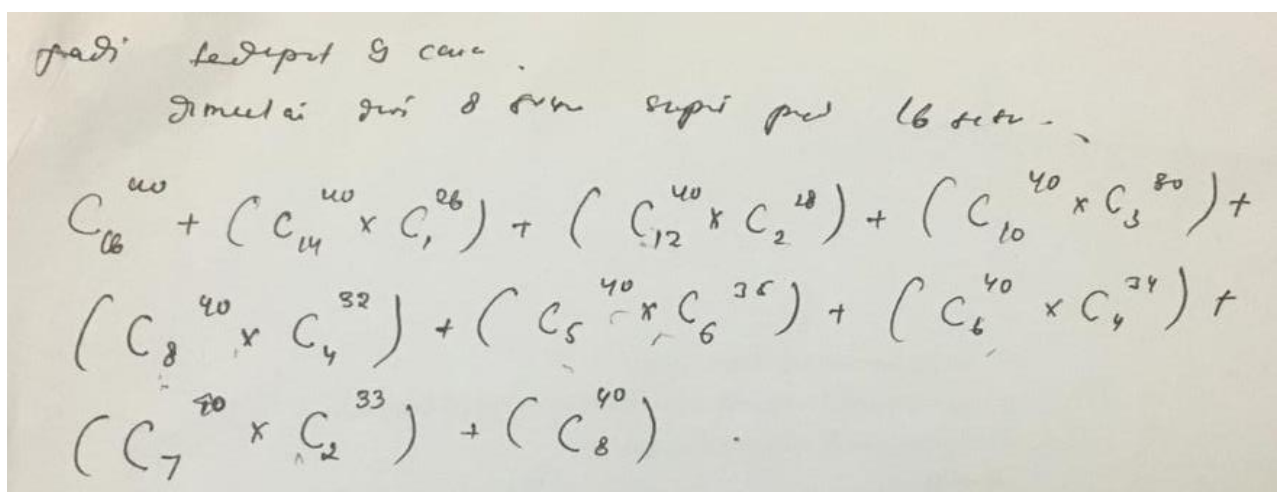

Gambar 12. Jawaban S2 yang Menunjukkan Fase Review 
Seperti fase-fase sebelumnya, gesture yang dilakukan S2 pada setiap tahap berpikir Mason sangat mempermudah usahanya dalam proses penemuan masalah. Bahkan pada fase review yaitu tahap pengecekkan kembali, S2 masih melakukan gesture yang sama seperti fase sebelumnya. Malah, ia menambah gesture representational agar dapat mendapatkan hasil yang dirasanya tepat. Berikut hasil wawancara S2 oleh peneliti.

"saat melakukan review jawaban, saya pelan-pelan mengecek dengan mengangan-angan yang saya tulis apakah sudah sesuai atau belum sambil sesekali menghitung kembali apakah yang saya tulis sudah tepat atau belum. Selain itu saya mengecek tanda yang telah saya buat apakah sudah sesuai atau belum. Hal ini saya lakukan agar lebih fokus dalam mengecekan jawaban dan tidak mengalami kesalahan, karena bagi saya mengecek ulang jawaban sangat penting sehingga saya harus teliti.” (W/S2/190120)

Wawancara diatas menunjukkan bahwa pada fase review ini membutuhkan ketelitian sehingga gesture sangat membantu dalam ketelitian tersebut. Gesture writing dengan menulis dan menandai informasi-informasi dapat menjadikan titik fokus terhadap apa yang dimaksud. Berdasarkan wawancara dengan S2 secara keseluruhan menunjukkan bahwa gesture terjadi secara refleks saat subjek ingin menandai dan memfokuskan hal-hal yang dianggap perlu dan penting dalam sebuah proses berfikir untuk menyeleseikan sebuah permasalahan.

\section{Fase Review}

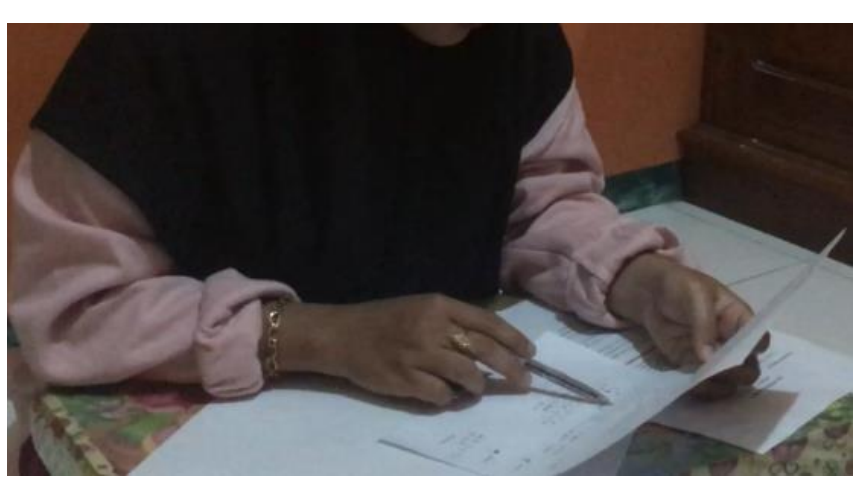

Pointing

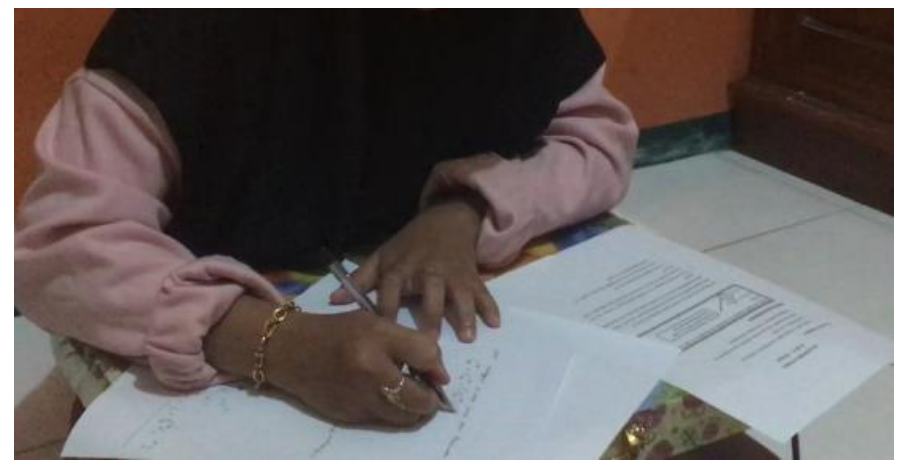

Writing

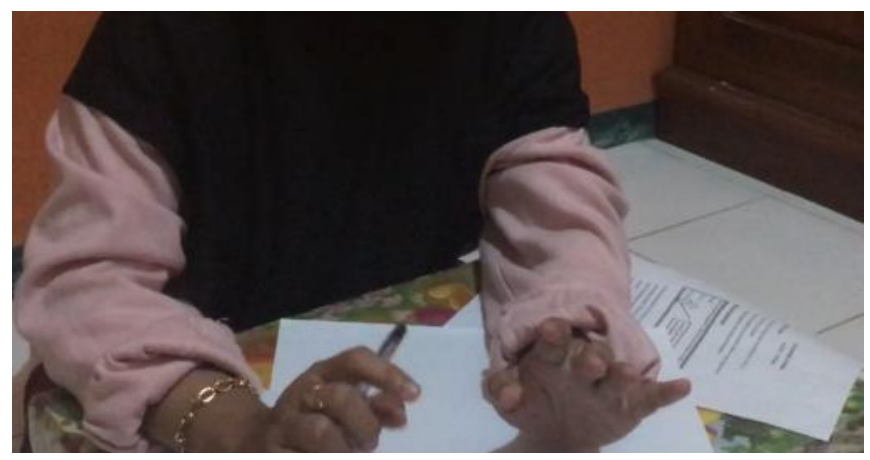

Representational

Gambar 13. Gesture Pointing, Representational, dan Writing yang Dilakykan S2 pada Fase Review

\section{PEMBAHASAN}

Hasil penelitian menunjukkan bahwa Mahasiswa dalam menyelesaikan masalah kombinatorika yang telah diberikan oleh peneliti, menunjukkan mahasiswa banyak melakukan gerakan-gerakan. Gerakan-gerakan yang dilakukan mahasiswa dapat digolongkan berdasarkan klasifikasi oleh (Alibali \& Nathan, 2007). Jenis gesture yang diklasifikasikan oleh Alibali \& Nathan (2007) yaitu gesture pointing, representational, dan writing. Ketiga gesture memiliki kegunaan yang berbeda-beda ketika seseorang melakukan gesture-gesture tersebut. Berikut akan dijelaskan terkait gesture yang dilakukan mahasiswa saat menyelesaikan masalah pada setiap fase entry, attack, dan review. 


\section{Gesture Mahasiswa Pada Fase Entry}

Gesture yang dilakukan mahasiswa pada fase entry yaitu pointing dan writing. Gesture pointing dalam penelitian ini adalah ketika seseorang menunjuk sesuatu (misalnya, petunjuk pengerjaan soal, maupun soal yang diberikan). Selanjutnya untuk gesture writing pada penelitian diartikan sebagai gerakan ketika seseorang menuliskan informasi berupa apa yang diketahui dan ditanya pada soal. Selain itu, berdasarkan hasil wawancara dari kedua subjek, menunjukkan bahwa merka melakukan gerakan-gerakan tersebut memiliki tujuan. Tujuan mereka melakukan gesture pointing yaitu untuk memfokuskan maupun ingin menandai informasi-informasi yang ada pada soal. Informasi-informasi tersebut berupa apa yang diketahui maupun yang ditanya pada soal. Beberapa hasil penelitian (Achadiyah, 2017; Alibali \& Nathan, 2011; Masita, Irawan, \& Sisworo, 2016) dalam pembahasannya menyatakan gesture pointing yang dilakukan oleh sebagian besar subjek penelitian bertujuan agar mempermudah dalam pemusatan perhatian dalam aspek penting yang menjadi bagian yang dapat mempermudah memahami persoalan untuk proses penemuan solusi dari masalah. Sedangkan, gesture writing dilakukan mahasiswa untuk mengutarakan apa yang dipahami atau informasi apa yang didapatnya pada masalah dalam bentuk lisan dan tulis. (Achadiyah, 2017; Alibali \& Nathan, 2011; Hardianto, Subanji, \& Rahardjo, 2016; Masita et al., 2016) menyatakan bahwa gesture writing atau menulis yang dilakukan siswa berguna untuk merepresentasikan ucapan-ucapan yang berhubungan dengan aljabar yang sulit diucapkan ke dalam tulisan.

\section{Gesture Mahasiswa Pada Fase Attack}

Berdasarkan hasil penelitian gesture yang dilakukan ke dua mahasiswa pada fase attack sama seperti pada saat fase entry, yaitu gesture pointing dan writing. Akan tetapi, tujuan mereka melakukan gesture tersebut memiliki tujuan yang berbeda dengan fase sebelumnya. Pada fase attack tujuan mereka melakukan gesture tersebut ialah untuk mempermudah dalam menyelesaikan perencanaan penemuan solusi. Tujuan gesture writing yaitu untuk menuliskan setiap langkah-langkah penyelesaian masalah. Hasil ini sejalan dengan Nisa (2017) yang mengatakan bahwa gesture yang dilakukan siswa membantu mereka dalam menjalankan rencana berupa langkah-langkah penyelesaian untuk menemukan solusi yang tepat.

\section{Gesture Mahasiswa Pada Fase Review}

Fase review merupakan tahap atau proses akhir dalam suatu penyelesaian masalah yang dilakukan oleh seseorang. Pada penelitian ini, fase review terlihat ketika subjek dapat mengecek kembali jawaban yang dibuatnya ataupun menuliskan kesimpulan dari apa yang ditanya pada masalah. Tujuan kedua mahasiswa melakukan gesture representational pada saat fase review yaitu untuk mengecek kembali perhitungan yang telah dibuat sebelumnya atau tahap attack. Selain itu, gesture yang terlihat pada fase review yaitu pointing dan writing. Tujuan gesture pointing dan writing yang dilakukan mahasiswa tersebut yaitu untuk mengecek kembali sambil menuliskan kesimpulan dari yang ditanyakan pada masalah. Hasil ini menunjukkan bahwa gesture representational, pointing, dan writing yang dilakukan mahasiswa membantu dalam mengecek kembali hasil yang diperoleh. Berkaitan dengan penjelasan tersebut, Nisa (2017) dalam hasil pembahasannya terkait penggunaan gesture siswa dalam memecahkan masalah mengatakan bahwa gesture pointing, writing, dan representational yang dilakukan siswa berguna untuk memahami masalah, merancang penyelesaian, dan menjalankan rencana (langkah-langkah penemuan solusi), serta dalam hal pengecekkan kembali. Selain itu, gesture yang dilakukan setiap subjek terkadang disertai dengan ucapan.

Pada penelitian ini, gesture pointing merupakan gesture yang paling sering muncul dalam menyelesaikan masalah yang diberikan. Hal tersebut sejalan dengan (Achadiyah, 2017; Alibali \& Nathan, 2011; Masita et al., 2016; Özçaliskan \& Dimitrova, 2013) yang mengatakan bahwa gesture pointing merupakan gesture yang sering digunakan oleh siswa. Gesture pointing yang dilakukan kedua mahasiswa ini biasanya dilakukan dengan menggunakan jari tengah, telunjuk, maupun bulpoin yang dipengangnya. Sejalan dengan Alibali \& Nathan (2007) mengatakan bahwa gesture pointing sering kali dilakukan dengan menggunakan jari tengah, jari telunjuk, jari manis, maupun alat yang sedang dipegangnya.

Gerakan-gerakan yang dilakukan oleh kedua mahasiswa tersebut biasanya disetai dengan ucapan dan gerakan itu sifatnya spontan maupun disengaja. Mereka melakukannya agar lebih dapat fokus ataupun lebih cepat dalam memahami soal yang diberikan. Pembahasan dari penelitian lain juga mengatakan hal yang sama, yaitu ketika siswa melakukan gerakan dalam menyelesaikan masalah biasanya disertai dengan ucapan biasanya memudahkan siswa dalam memecahkan masalah khususnya pada saat memahami masalah (Cook \& Goldin-meadow, 2006). Pada penelitian ini juga ditemukan bahwa gesture yang dilakukan di setiap fase Mason ada yang berbeda-beda. Reynolds \& Reeve (2002) mengatakan gesture yang dilakukan oleh siswa bermacam-macam dalam mempermudah penemuan solusi.

\section{SIMPULAN}

Hasil penelitian menunjukkan bahwa dua mahasiswa yang menyelesaikan masalah kombinatorika dengan benar melakukan gesture pointing, representational dan writing. Gesture yang dilakukan dua mahasiswa tersebut sifatnya spontan maupun disengaja. Selain itu, gesture yang dilakukan biasanya disertai dengan ucapan agar lebih fokus dalam memahami masalah yang diberikan. Terkait tahap berpikir Mason yaitu entry, attack, dan review, dua mahasiswa melakukan kesamaan jenis gesture di setiap fasenya. Pada fase entry dan attack, gesture yang dilakukan ke-2 mahasiswa itu yaitu gesture pointing dan writing. Sedangkan pada fase review gesture yang dilakukan yaitu gesture representational. Penelitian ini juga ditemukan 
tujuan-tujuan mengapa mereka melakukan gesture tersebut. Pada fase entry gesture poitng dilakukan untuk memfokuskan atau menandai informasi yang terdapat pada masalah. Selanjutnya, pada fase writing, gesture ini dilakukan pada saat subjek menuliskan apa yang diketahui maupun ditanya. Terkahir, pada fase review gesture yang dilakukan salah satunya represenatational. Tujuan gesture tersebut untuk mengecek kembali ke tempat perhitungan sebelumnya pada fase attack.

Pada penelitian ini masih membutuhkan kajian yang lebih mendalam dan subjek yang lebih luas sehingga peneliti berikutnya dapat merumuskan teori baru mengenai gesture pada saat menyelesaikan masalah berdasarkan kerangka berpikir Mason. Selain itu, penggunaan instrumen soal sebaiknya dapat lebih mengeksplor kemunculan gesture saat menyelesaikan masalah pada setiap fase Mason. Bagi peneliti selanjutnya diharapkan dapat menggunakan mata pelajaran yang lainnya sebagai perbandingan, apakah pada setiap fase Mason memiliki gesture yang sama seperti halnya pada materi matematika.

\section{DAFTAR RUJUKAN}

Abdillah, A., Nusantara, T., Subanji, S., \& Susanto, H. (2018). Proses Berpikir Siswa Dalam Menyelsaikan ILL Structured Problems Matematis. Artikel Seminar Nasional.

Achadiyah, N. L. (2017). Gestur Siswa Sekolah Menengah Pertama dalam Memecahkan Masalah Matematis secara Berkelompok. Suska: Journal of Mathematics Education, 3(1), 49-56.

Alibali, M. W., \& Nathan, M. J. (2007). Teachers' Gestures as a Means of Scaffolding Students' Understanding: Evidence From an Early Algebra Lesson, 349-366.

Alibali, M. W., \& Nathan, M. J. (2011). Embodiment in Mathematics Teaching and Learning : Evidence From Learners' and Teachers' Gestures. Journal of the Learning Sciences, 37-41. https://doi.org/10.1080/10508406.2011.611446

Alibali, M. W., Spencer, R. C., Knox, L., \& Kita, S. (2011). Spontaneous Gestures Influence Strategy Choices in Problem Solving. Association For Psychological Science, 9(22), 1138-1144. https://doi.org/10.1177/0956797611417722

Arzarello, F., Paola, D., Robutti, O., \& Sabena, C. (2009). Gestures as Semiotic Resources in the Mathematics Classroom. Educ Stud Math, 70, 97-109. https://doi.org/10.1007/s10649-008-9163-z

Beilock, S. L., \& Goldin-Meadow, S. (2010). Gesture Changes Thought by Grounding It in Action. Association for Psychological Science, 11(21), 1605-1610. https://doi.org/10.1177/0956797610385353

Broaders, S. C., Cook, S. W., Mitchell, Z., \& Goldin-meadow, S. (2007). Making Children Gesture Brings Out Implicit Knowledge and Leads to Learning. Journal of Experimental Psychology: General, 136(4), 539-550. https://doi.org/10.1037/0096-3445.136.4.539

Cook, S. W., \& Goldin-meadow, S. (2006). The Role of Gesture in Learning: Do Children Use Their Hands to Change Their Minds ?, 7(2), 211-232.

Francaviglia, M., \& Servidio, R. (2011). Gesture as a Cognitive Support to Solve Mathematical Problems. Scientific Research, 2(2), 91-97. https://doi.org/10.4236/psych.2011.22015

Hardianto., Subanji., \& Rahardjo, S. (2016). Analisis Penggunaan Gesture untuk Memperbaiki Kesalahan Konsep Siswa dalam Proses Diskusi Pemecahan Masalah PISA. Pedagogy, 1(1), 36-47.

Khamidah, L. (2017). Pemahaman Konseptual dan Pengetahuan Prosedural Siswa Kelas VIII dalam Penyelesaian Masalah Matematika pada materi Sistem Persamaan Linier Dua Variabel di SMPN 7 Kediri. Simki-Techsain, 01(08), 2-10.

Kusaeri, Lailiyah, S., Arrifadah, Y., \& Hidayati, N. (2018). Proses Berpikir Siswa dalam Menyelesaikan Masalah Matematika Berdasarkan Teori Pemrosesan Informasi. Suska Journal of Mathematics Education, 4(2), 125-141.

Masita, T. N., Irawan, E. B., \& Sisworo. (2016). Gesture Menunjuk dan Represntasional Siswa sesuai dengan Tahapn Berpikir Van Hiele. Jurnal Pendidikan: Teori, Penelitian, dan Pengembangan, 1(2), 271-280.

Mcneill, D. (2014). Hand and Mind: What Gestures Reveal About Thought, (June 1994). https://doi.org/10.2307/1576015

Mustafa, S., Nusantara, T., Subanji, \& Irawati, S. (2016). Mathematical Thinking Process of Autistic Students in Terms of Representational Gesture. International Education Studies, 9(6), 93-107. https://doi.org/10.5539/ies.v9n6p93

Nisa, Hikmah M. (2017) Gesture Siswa Bergaya Kognitif Fiel Independent dan Field Dependent dalam Memecahkan Masalah Matematika Secara Berkelompok. Tesis tidak diterbitkan. Universitas Negeri Malang, Malang.

Ng, O., \& Sinclair, N. (2013). Gesture and Temporality: Children's Use of Gesture on Spatial Transformation Tasks. Proceedings of the 37th Conference of the International Group for the Psychology of Mathematics Education, 3, 361-368.

Özçaliskan, S., \& Dimitrova, N. (2013). How Gesture Input Provides a Helping Hand to Language Development, 4(34), 227236.

Radford, L. (2009). Why do Gestures Matter? Sensuous Cognition and the Palpability of Mathematical Meanings. Educational Studies in Mathematics, 70, 111-126. https://doi.org/10.1007/s10649-008-9127-3

Reynolds, F. J., \& Reeve, R. A. (2002). Gesture in collaborative mathematics problem-solving. Journal of Mathematical Behavior, 20, 447-460.

Safrida, L. N., Susanto, \& Kurniati. (2015). Analisis Proses Berpikir Siswa dalam Pemecahan Masalah Terbuka Berbasis Polya Sub Pokok Bahasan Tabung Kelas IX SMP Negeri 7 Jember. Kadikma, 6(1), 25-38.

Sari, D. N., \& Saragih, N. A. (2019). Analisis Proses Berpikir Mahasiswa Pendidikan Matematika Dalam Menyelesaikan Masalah Matematika Tahun Akademik 2018/2019. Jurnal Math Education Nusantara, 2(2), 107-112.

Subanji. (2011). Teori Berpikir Pseudo Penalaran Kovariasional. Malang: UM Press. 
Sucipto, L. (2018). Proses Berpikir Analogi Mahasiswa dengan Gaya Belajar Field Dependence dan Gaya Belajar Field Independence dalam Memecahkan Masalah Matematika. JARTIKA: Jurnal Riset Teknologi dan Inovasi Pendidikan, 1(1), 37-51.

Sulistyorin, Y., Argarini, D. F., \& Yazidah, N. I. (2018). Analisis Kesalahan dalam Memecahkan Masalah Kombinatorika Ditinjau dari Gaya Kognitif. Jurnal Pendidikan Matematika FKIP Universitas Muhammadiyah Metro, 7(1), 114-123.

Widyastuti, R., Usodo, B., \& Riyadi. (2007). Proses Berpikir Siswa SMP dalam Menyelesaikan Masalah Matematika Berdasarkan Langkah-langkah Polya Ditinjau dari Adversity Quotient Tipe Climber. Al-Jabar: Jurnal Pendidikan Matematika, 6(2), 239-249.

Yani, M., Ikhsan, M., \& Marwan. (2016). Proses Berpikir Siswa Sekolah Menengah Pertama dalam Memecahkan Masalah Matematika Berdasarkan Langkah-langkah Polya Ditinjau dari Adversity Quotient. Jurnal Pendidikan Matematika, 10(1), 43-58.

Yoon, C., Thomas, M. O. J., \& Dreyfus, T. (2011). Gestures and Insight in Advanced Mathematical Thinking. International Journal of Mathematical Education in Science and Technology, 42, 891-901. https://doi.org/10.1080/0020739X.2011.608861 